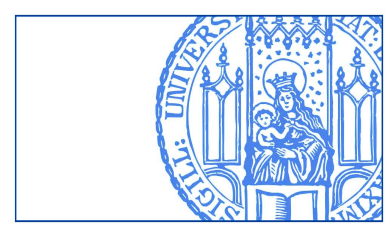

Schlicht, Ekkehart:

Selection Wages and Discrimination

Munich Discussion Paper No. 2009-14

Department of Economics

University of Munich

Volkswirtschaftliche Fakultät

Ludwig-Maximilians-Universität München

Online at https://doi.org/10.5282/ubm/epub. 10990 


\title{
Selection Wages and Discrimination
}

\author{
Ekkehart Schlicht ${ }^{*}$
}

Applicants for any given job are more or less suited to fill it, and the firm will select the best among them. Increasing the wage offer attracts more applicants and makes it possible to raise the hiring standard and improve the productivity of the staff. Wages that optimize on the trade-off between the wage level and the productivity of the workforce are known as selection wages. As men react more strongly to wage differentials than females, the trade-off is more pronounced for men and a profitmaximizing firm will offer a higher wage for men than for women in equilibrium.

Keywords: Discrimination, selection wages, efficiency wages, hiring standards, monopsony, employment criteria, wage posting, Reder competition

Journal of Economic Literature Classification: J31, J7, B54, D13, D42

*Department of Economics, University of Munich, Schackstr. 4, 80539 Munich, Germany, www.lrz.de/ ekkehart, schlicht@lmu.de. I thank Roberto Cruccolini, Boris Hirsch, Elmar Nubbemeyer, Emmi Schlicht, Claus Schnabel, Christoph Stoeckle, and Mehrdad Vahabi for helpful comments on an earlier version. 


\section{Contents}

Introduction • 1 Selection Wages $\bullet 2$ Discrimination $\bullet 3$ The Social Multiplier and Market Discrimination $\bullet 4$ Quotas and Equal Pay Enforcement $\bullet 5$ Wage Differentials and Social Stereotypes $\bullet$ Conclusion $\bullet$ References $\bullet$ Parameters Used For The Illustrations

\section{Introduction}

Labor is heterogeneous: Applicants for any given job are differently suited to fill it. Faced with a number of applicants, a firm selects the best among them. Increasing its wage offer attracts more applicants and makes it possible to raise the hiring standard, thereby improving the productivity of the staff. Wages that optimize on the trade-off between the wage level and the productivity of the workforce are known as selection wages-a variant of efficiency wages (SсHLicht 2005, 2007). The mechanism is explained in Section 1.

If the trade-off between the wage level and labor productivity differs for males and females, different wages for males and females will result and group discrimination obtains. This is to be expected. Empirical studies suggest that women and men differ in responsiveness to wage changes: The number of female applicants for a job opening reacts less to wage changes than that of males (Manning 2005, Ch. 7, Sulis 2007, Hirsch et al. 2008, Hirsch et al. 2009). Hence an increased wage offer for males will attract more applicants and will permit a more pronounced tightening of the hiring standard for males as compared to females. This renders it worthwhile for a profit-maximizing firm to offer a lower wage for women than for men. Section 2 develops this idea.

The core behavioral assumption used here-a different responsiveness of males and females to wage differentials-accords nicely with prevailing social roles and stereotypes encountered in many economies, that tie women more closely to the home than men. Such sterotypes, shared by men an women alike, effectively reduce the labor market options of women and render them less responsive to wage differentials. According to the view proposed here, this induces discrimination. Such discrimination feeds back on social roles and stereotypes. The process is explained in Section 3. A brief discussion of quotas and laws that enforce equal pay follows in Section 4.

The source of discrimination-the behavioral impact of social roles and stereotypes-is sometimes portrayed as a matter of "tastes." This seems misleading, as such parlance assimilates widely shared attitudes and convictions to private preferences that have no bearing on others. Yet if such "tastes" are envisioned as conditioned by social roles and expectations, prevailing discrimination theories contribute to our understanding of the phenomenon. Section 5 comments on these contiguous issues. A conclusion follows. 


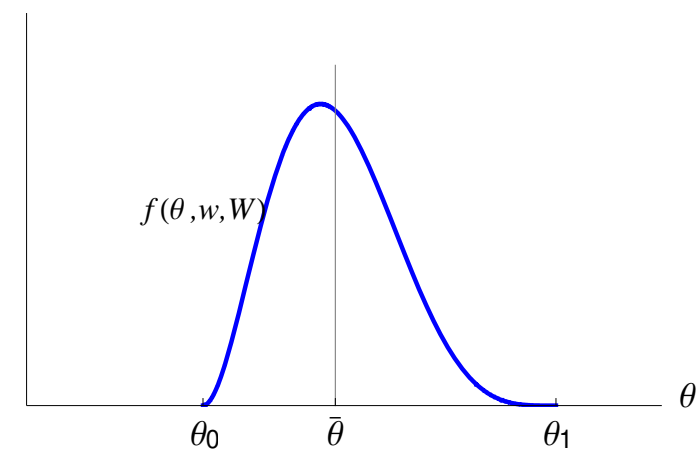

(a)

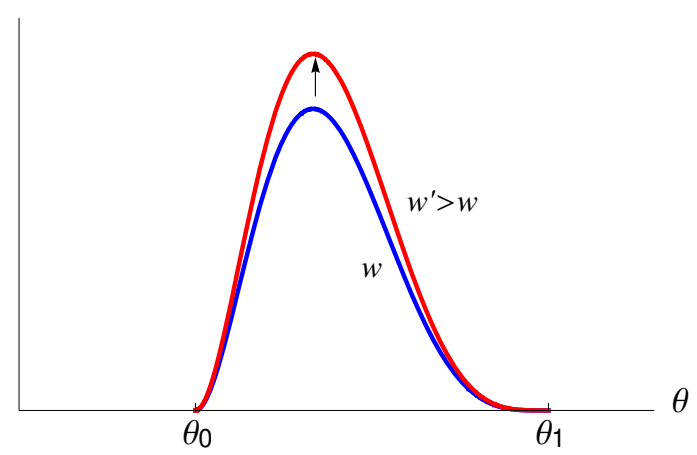

(b)

Figure 1: (a) The labor supply function $f(\theta, w, W)$ gives the number of workers of productivity $\theta$ willing to work at the firm for the wage $w$, given the market wage level $W$. Average productivity is $\bar{\theta}$. (b) If the firm increases the wage offer $w$, supply increases for all grades of labor. A decrease in the market wage level $W$ would entail a similar change.

\section{Selection Wages}

Consider a labor market where workers differ in productivity. There are a number of firms operating in the market. Each of these firms employs a number of workers and offers a certain wage. In the aggregate, this results in a certain level of employment $N$ and a certain average market wage rate $W$.

Labor supply for a single firm is described by a function

$$
f(\theta, w, W)>0 .
$$

It gives the number of workers of productivity $\theta$ willing to work at that firm for the wage $w$, given the market wage level $W$. For simplicity of exposition, all variables are taken as real. The supply function is the continuous analogue of a histogram, akin to a density function. Productivities $\theta$ range from $\theta_{0}$ to $\theta_{1}$ (Figure 1 (a)).

We assume that an increase of the wage offer $w$ increases the supply of all grades of labor $\left(f_{w}>0\right)$. This effect decreases with an increasing wage offer $\left(f_{w w}<0\right)$. For any given wage offer $w$, an increase in the market wage level $W$ decreases supply as this indicates an improvement in outside options $\left(f_{W}<0\right)$. An increase of the market wage level acts like a decrease of the wage offer on the marginal effect of wage increases $\left(f_{w W}>0\right)$. Figure 2 illustrates the effect of wage changes on supply. Formally we have

$$
\theta \epsilon\left[\theta_{0}, \theta_{1}\right], f_{w}>0, f_{w w}<0, f_{W}<0, f_{w W}>0 .
$$


Note that labor supply is to be conceived as comprising all workers that could be hired by the firm under consideration, irrespectively of whether they are employed elsewhere, or unemployed.

The firm has a technologically fixed number of jobs $n$ to fill. The minimum wage that is required to fill these jobs is implicitly defined by

$$
n=\int_{\theta_{0}}^{\theta_{1}} f\left(\theta, w_{0}(W), W\right) d \theta
$$

and is denoted by $w_{0}(W)$. It is the competitive wage. Because of

$$
w_{0}^{\prime}=-\frac{\int_{\theta_{0}}^{\theta_{1}} f_{W} d \theta}{\int_{\theta_{0}}^{\theta_{1}} f_{w} d \theta}>0
$$

the competitive wage is an increasing function of the market wage level $W$.

The firm has to pay at least the competitive wage $w_{0}$ in order to fill its vacancies, but it can offer more. If it does so, it will improve the number of applicants, including more productive applicants. This makes it possible to screen workers and select only the best applicants, that is, only applicants with productivity above a certain threshold value $s(w, W)$ that is implicitly defined by the equation

$$
n=\int_{s(w, W, n)}^{\theta_{1}} f(\theta, w, W) d \theta
$$

The threshold $s(w, W, n)$ is the hiring standard. From (4) we obtain

$$
s_{w}=\frac{1}{f} \int_{s}^{\theta_{1}} f_{w} d \theta>0, s_{W}=\frac{1}{f} \int_{s}^{\theta_{1}} f_{W} d \theta<0, s_{n}=-\frac{1}{f}<0 .
$$

The firm can increase its hiring standard if it offers a higher wage rate $\left(s_{w}>0\right)$. If the market wage level increases, supply at the given wage offer is reduced and the firm must lower its hiring standard $\left(s_{W}<0\right)$. Further, the hiring standard is to be reduced if more workers are to be hired $\left(s_{n}<0\right)$. Note that workers with productivity less than $s$ that are not hired are not necessarily unemployed, as they may be employed elsewhere, although they would prefer employment at the firm under consideration, given its wage offer. 
The wage rate $w$ and a market wage level $W$ imply average productivity

$$
a(w, W, n)=\frac{\int_{s(w, W, n)}^{\theta_{1}} \theta f(\theta, w, W) d \theta}{\int_{s(w, W, n)}^{\theta_{1}} f(\theta, w, W) d \theta}=\frac{1}{n} \int_{s(w, W, n)}^{\theta_{1}} \theta f(\theta, w, W) d \theta .
$$

This is the productivity curve depicting the relationship between the wage offer and the productivity of the firm's workforce (Figure 3$).{ }^{1}$ Its derivatives are

$$
\begin{aligned}
a_{w} & =\frac{1}{n} \int_{s}^{\theta_{1}}(\theta-s) f_{w} d \theta>0 \\
a_{w w} & =\frac{1}{n} \int_{s}^{\theta_{1}}(\theta-s) f_{w w} d \theta-\frac{1}{n f}\left(\int_{s}^{\theta_{1}} f_{w} d \theta\right)^{2}<0 \\
a_{W} & =\frac{1}{n} \int_{s}^{\theta_{1}}(\theta-s) f_{W} d \theta<0 \\
a_{w W} & =\frac{1}{n} \int_{s}^{\theta_{1}}(\theta-s) f_{w W} d \theta-\frac{1}{n f}\left(\int_{s}^{\theta_{1}} f_{W} d \theta\right)\left(\int_{s}^{\theta_{1}} f_{w} d \theta\right)>0 \\
a_{n} & =-\frac{1}{n^{2}} \int_{s}^{\theta_{1}}(\theta-s) f d \theta=-\frac{1}{n}(a-s)<0
\end{aligned}
$$

where $s=s(w, W, n)$. In other words: Average productivity increases if the wage offer $w$ increases. The effect diminishes with an increasing wage rate. An increase in the average wage level $W$ works similar to a decrease in the wage offer $w$, as it improves outside options of the workers. This implies the third and forth inequalities in (7). Finally we note for later use that an increase in $n$ decreases average productivity.

The firm faces, thus, a trade-off between the wage level and the productivity achievable. The argument is illustrated in Figure 2. The resulting productivity curve is depicted in Figure (a). According to (3) and (7) the competitive wage increases with an increasing market wage level $W$, and the productivity curve shifts down (Figure 3 (b)).

Given the product price $p$, the firm will maximize the the difference between the productivity of its staff, valued at the market price of the product, and labor costs by selecting the appropriate wage rate. ${ }^{2}$

$$
p a(w, W, n)-w \rightarrow \max _{w}
$$

We assume that the product price is high enough to assure profitability. The first-order

\footnotetext{
1 The concept of the productivity curve has been introduced in Schlicht $(1978,393) .2$ The product price $p$ is to be understood as the contribution margin of a worker with $\theta=1$, that is, the receipt for the production produced by such a worker minus variable non-labor costs.
} 


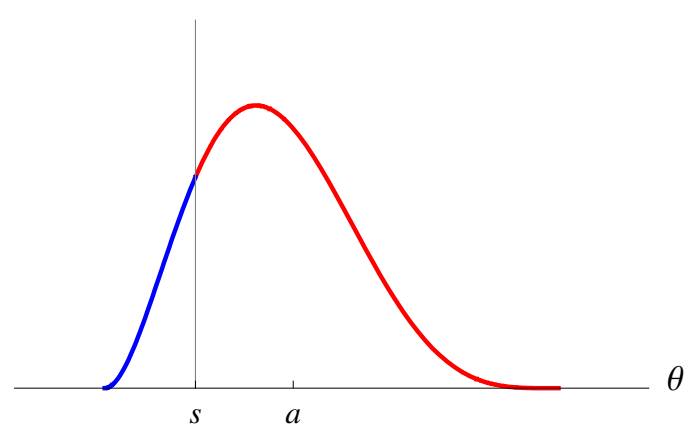

(a)

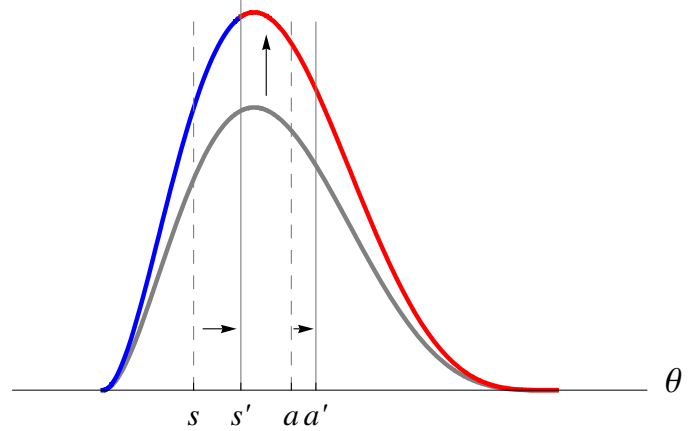

(b)

Figure 2: (a) Employment $n$ implies a hiring standard $s$ and average productivity $a$. Workers with productivities below $s$ are not hired. (b) Increasing the wage offer increases supply and permits the firm to increase its hiring standard to $s^{\prime}$. This entails an increased average productivity $a^{\prime}$.

condition for a profit maximum is

$$
p a_{w}-1=0 .
$$

As $a_{w w}<0$, the second order condition is satisfied. Equation (9) may alternatively be written as

$$
\varepsilon(w, W, n)=\frac{w}{p a}
$$

with

$$
\varepsilon(w, W, n):=\frac{\partial a}{\partial w} \frac{w}{a}
$$

as the elasticity of productivity. Condition (10) states that the elasticity of productivity is to be equal to the ratio of labor costs to sales minus variable costs. This elasticity condition differs from the Solow-condition usually encountered in efficiency wage theory that requires the elasticity of productivity to equal one in equilibrium (Solow 1979, 80; Schlicht 1978, 340). The difference is due to the different (and, it is hoped, more realistic) assumption regarding the technology of the firms.

Equation (9) implies an optimal wage rate

$$
w^{*}=w(W, p)
$$

with is referred to as the wage. Its determination is depicted in Figure 3 (c). Regarding its 


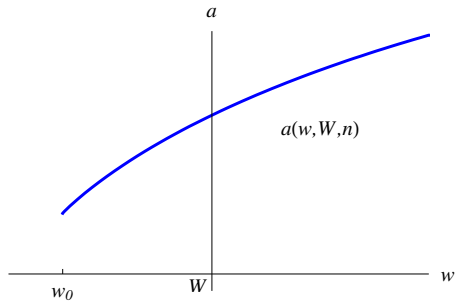

(a)

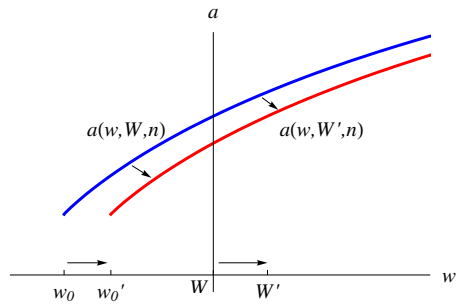

(b)

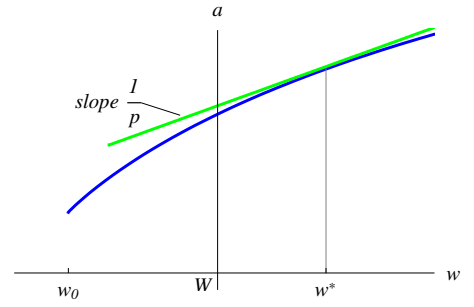

(c)

Figure 3: (a) The minimum wage the firm must pay is the competitive wage $w_{0}$. Increasing the wage above that level permits a tightening the hiring standard, engendering increased productivity, as described by the productivity curve $a(w, W, n)$. (b) An increase in the wage level from $W$ to $W^{\prime}$ shifts the productivity curve down and increases the competitive wage from $w_{0}$ to $w_{0}^{\prime}$. (c) The wage $w^{*}$ is given by the condition that the slope of the productivity curve equals $\frac{1}{p}$.

properties we find

$$
\begin{aligned}
w_{W}^{*} & =-\frac{a_{w W}}{a_{w w}}>0 \\
w_{p}^{*} & =-\frac{a_{w}}{p a_{w w}}>0 .
\end{aligned}
$$

In other words: An increasing market wage will induce the firm to offer a higher wage rate, and an increasing product price will increase the wage offer, too.

\section{Discrimination}

Now consider the case of two groups of workers, males and females. Index all symbols referring to females by $f$ and those referring to males by $m$. Hence $f^{f}$ and $f^{m}$ denote the respective supply functions, $W^{f}$ and $W^{m}$ refer to the respective market wage levels, $w^{f}$ and $w^{m}$ stand for the firm's wage offers, and so forth.

The firm has to man $n$ jobs by hiring men and women:

$$
n=n^{f}+n^{m}
$$

With a hiring standard $s^{f}$ for women and a hiring standard $s^{m}$ for males, the average productivity of females is $a^{f}$ and that of males is $a^{m}$. The productivity of the work force is thus

$$
a=\frac{n^{f}}{n} a^{f}\left(w^{f}, W^{f}, n^{f}\right)+\frac{n^{m}}{n} a^{m}\left(w^{m}, W^{m}, n^{m}\right) .
$$


The average wage rate is

$$
w=\frac{n^{f}}{n} w^{f}+\frac{n^{m}}{n} w^{m} .
$$

The firm wants to maximize profits $p a-w$ which is:

$$
p\left(\frac{n^{f}}{n} a^{f}\left(w^{f}, W^{f}, n^{f}\right)+\frac{n^{m}}{n} a^{m}\left(w^{m}, W^{m}, n^{m}\right)\right)-\left(\frac{n^{f}}{n} w^{f}+\frac{n^{m}}{n} w^{m}\right)
$$

with regard to $w^{f}, w^{m}, n^{f}$, and $n^{m}$ under the constraint (12). This gives rise to the Lagrangian

$$
\begin{aligned}
\mathcal{L}=p & \left(\frac{n^{f}}{n} a^{f}\left(w^{f}, W^{f}, n^{f}\right)+\frac{n^{m}}{n} a^{m}\left(w^{m}, W^{m}, n^{m}\right)\right) \\
& -\left(\frac{n^{f}}{n} w^{f}+\frac{n^{m}}{n} w^{m}\right)+\lambda\left(n-n^{f}-n^{m}\right) .
\end{aligned}
$$

The first-order conditions for a maximum are

$$
\begin{aligned}
\frac{\partial \mathcal{L}}{\partial w^{i}} & =\frac{n^{i}}{n}\left(p a_{w_{i}}^{i}-1\right)=0 \\
\frac{\partial \mathcal{L}}{\partial n^{i}} & =\frac{p}{n}\left(a^{i}+n^{i} a_{n_{i}}^{i}\right)-\frac{w^{i}}{n}-\lambda=0, \quad i=f, m .
\end{aligned}
$$

In view of (7) this implies

$$
\begin{aligned}
a_{w^{f}}^{f} & =a_{w^{m}}^{m}=\frac{1}{p} \\
p \cdot s\left(w^{f}, W^{f}, n^{f}\right)-w^{f} & =p \cdot s\left(w^{m}, W^{m}, n^{m}\right)-w^{m}
\end{aligned}
$$

The first condition is similar to the condition (9). It states the group-specific wage is determined by the condition that the slope of the productivity curve is equal to $\frac{1}{p}$. Hence wages will be the same if the productivity curves are the same. The second condition says that the difference between the value of the hiring standard and the wage must be the same for both groups.

Consider the case that males and females have identical supply functions and the market wage levels $W^{f}$ and $W^{m}$ are the same. In this case, the symmetric solution $w^{f}=w^{m}$ and $s\left(w^{f}, W^{f}, n^{f}\right)=s\left(w^{m}, W^{m}, n^{m}\right)$ will satisfy (14) and (15). No discrimination would occur. It can readily be seen that this result carries over to the case that labor supply for 
females is just a fraction $\alpha$ of the supply of males, amounting to $f^{f}=\alpha f^{m}$ for all $\theta, w, W$ and $n^{f}=\alpha n^{w}$.

However, this equal treatment will be ruled out if supply behavior of females differs from that of males. It has been hypothesized and empirically supported that this is indeed the case (Manning 2005, Ch. 7, Sulis 2007, Hirsch et al. 2008, Hirsch et al. 2009): Women seem to place more weight on non-monetary job attributes, such as proximity to home and reasonable working hours, than men do. This would imply that $f_{w}^{f}(\theta, w, W)<$ $f_{w}^{m}(\theta, w, W)$ for all $(\theta, w, W)$, entailing $a_{w}^{f}(w, W, n)<a_{w}^{m}(w, W, n)$.

Theorem: If, for some values $(w, W)$, the following assumptions are satisfied, the Lagrange conditions (14) and (15) are violated:

$$
\begin{aligned}
& f^{f}(\theta, w, W)=f^{m}(\theta, w, W) \text { for all } \theta \in\left[\theta_{0}, \theta_{1}\right] \\
& f_{w}^{f}(\theta, w, W)<f_{w}^{f}(\theta, w, W) \text { for all } \theta \in\left[\theta_{0}, \theta_{1}\right] .
\end{aligned}
$$

In other words: If the supply and the distribution of productivities of men and women is identical at some common wage offer $w$, given some shared market wage rate $W$, the individual firm will have an incentive to offer discriminatory wages.

Proof: If the market wage level $W$ and the wage rate $w$ are identical for men an women, condition (17) implies that the same hiring standard $s$ is applied to men and women. Hence the same fraction of men and women are employed and their average productivities will be the same. As the women's labor supply exhibits a lower sensitivity to wage changes, the average sensitivity of supply, taken in both cases over the range of productivities $\left[s, \theta_{1}\right]$ must be less for women than for men. This violates (14). QED.

It can readily be seen that the theorem carries over to the case that labor supply for females is just a fraction $\alpha$ of males, amounting to $f^{f}=\alpha f^{m}$ and $f_{w}^{f}<\alpha f_{w}^{m}$ for all $\theta$ and some $w, W$.

To elucidate matters further, consider the case that men and women are lumped together. This results in a supply function

$$
f(\theta, w, W)=f^{f}(\theta, w, W)+f^{m}(\theta, w, W)
$$

and wage setting would proceed as in Section 1. We call this the pooling equilibrium. Assume that at this equilibrium (18) obtains, viz. that at the common wage rate $w$ the forthcoming productivity distribution of males and females is just the same. Average productivity would be

$$
a=\frac{1}{2} a^{f}+\frac{1}{2} a^{m}
$$

where employment levels for males and females $n^{f}=n^{m}=\frac{1}{2} n$ are induced by the shared hiring standard $s$. Regarding the sensitivity of productivity to wage changes, we would have 
(still with the same hiring standard and wage for men and women)

$$
a_{w}=\frac{1}{2} a_{w}^{f}+\frac{1}{2} a_{w}^{m} .
$$

As $a_{w}=\frac{1}{p}$ from (9) and $a_{w}^{f}<a_{w}^{m}$ from (18) we must have, in violation of (16),

$$
a_{w}^{f}<\frac{1}{p}<a_{w}^{m}
$$

By lowering wages for women and increasing wages for men while keeping employment levels and the average wage unchanged, the firm can increase its profits: Increasing the wage for males by $\Delta$ while keeping the employment of males and females unchanged requires a reduction of the wage for women by the same amount. Such a change in payments would leave the wage bill unchanged. Yet the induced change in average productivity is

$$
\frac{1}{2}\left(a_{w}^{f}-a_{w}^{m}\right) \Delta>0 .
$$

Hence the firm can, by introducing a discriminatory wage policy, increase the productivity of its work force without changing the wage bill. Such a change goes along with tightening the hiring standard for males and loosening the hiring standard of females in order to accommodate the change.

The argument carries over to the case that supply of females is not identical to that of males, but only a fraction of the supply of males for all $\theta$ and the equilibrium wage obtained under pooling.

Once the firm is offering different wages, it will have an incentive to adjust the share of women and men in total employment in order to meet condition (17).

\section{The Social Multiplier and Market Discrimination}

According to the view expounded here, wage discrimination will be triggered by differences in supply behavior of males and females, even if no initial discrimination exists on the market level. As the argument applies to all firms in the market, we would expect market wage levels for men and women to diverge. This will feed back on discrimination.

According to (11), an increased wage level for one of the groups will push the corresponding optimal wage offer of the firm up, and vice versa., and the initial discrimination will be augmented at the market level. This process is known as the "social multiplier" (SCHLicht, 1981, Glaeser et al., 2003 and, regarding discrimination, Schlicht, 1982). Due to this multiplier, we would expect significant discrimination to emerge in the market. 
Such a process may be seen as a kind of self-confirming cycle: The traditional sexual division of labor ties women more closely to the home and thereby generates wage discrimination of women. This supplies an incentive for maintaining the traditional pattern. It appears as normality, and such normality re-establishes the social norm. As KaHneman et al. (1986, 730f.) put it: "Psychological studies of adaptation suggest that any stable state of affairs tends to become accepted eventually, at least in the sense that alternatives to it no longer readily come to mind. Terms of exchange that are initially seen as unfair may in time acquire the status of a reference transaction. Thus, the gap between the behavior that people consider fair and the behavior that they expect in the marketplace tends to be rather small." Different social roles for men and women are reconfirmed this way and induce wage discrimination in turn.

\section{Quotas and Equal Pay Enforcement}

A possibility of fighting discrimination would be to introduce a quota system, but this would not eliminate discrimination. Consider the situation envisaged in the proof of the theorem: At a common wage rate, the skill distribution of both populations are identical, but women react less to wage changes than men do. As discussed above, this would create an incentive for firms to pay women less than males. A quota system must be supported by an anti-discrimination law that enforces equal pay for men and women doing the same job.

Such anti-discrimination law would by itself enforce identical hiring standards for both groups and render a quota system superfluous. Yet the incentive to discriminate would not be removed, and firms may actually implicitly discriminate in a system where explicit wage discrimination is prohibited by law. This could be done by creating formally different positions that are paid differently yet involve identical tasks. Another way to circumvent anti-discrimination regulations could be to promote women more languidly, etc. Yet we can expect such laws to mitigate discrimination to some degree. ${ }^{1}$

Note that the statistical theory of discrimination would require a quota system along with equal pay enforcement in order to avoid discrimination through segregation. The selection wage theory, as well as the closely related monopsony theory, differ here, as no quota system seems to be required.

\footnotetext{
1 It is difficult to reach definite welfare conclusions in the model presented here. Yet the fact that welfare can be increased in the closely related "dynamic monopsony" discrimination model by introducing an anti-discrimination law suggest that a similar result may hold true in the wage context; see SCHLICHT (1982, 77f.). Yet this is a mere conjecture. Further analysis seems to be required here.
} 


\section{Wage Differentials and Social Stereotypes}

Wage discrimination is socially particularly objectionable if it is based on social prejudices and stereotypes that are unrelated to productivity differentials between the groups involved. (We do not, as a rule, object to more productive workers being better paid, unless pay differentials get glaringly out of proportion.) Hence a central tenet of any theory of labor market discrimination must be to establish a link between wage differentials and social stereotypes.

The "taste" theory of discrimination assumes social stereotypes to shape preferences (BECKER, 1971). Yet it remains unclear in which way such stereotyped preferences affect behavior and can persist in the marketplace. If the joining of different types of workers is costly because members of one group (males) share an aversion against working together with members of the other group (women), the income of male workers who work together with females ought to be higher than that of males working in an exclusively male environment. This has not been observed. The other possible outcome would be segregation. In contrast, the wage theory of discrimination would permit discrimination without segregation, and without wage differentials between segregated and non-segregated environments for males.

In a more fundamental way, the "taste" theory of discrimination seems highly problematic, mainly for two reasons: The first is that discriminatory preferences are taken as given. Yet, as MARshall (1920, vi.v.ix) has observed in a related context, "a great influence is exerted by custom and public opinion which are themselves the outcome of the experience of past generations." In other words: The social norms that trigger discrimination are endogenous, they are not arbitrary, and cannot be taken as givens for purposes of long-term analysis.

The other objection to assimilating discriminatory norms to personal tastes pertains to the issue of externalities, "taste externalities," if you will. While it does not matter to me if you prefer tea over coffee at breakfast, it makes a difference for women and men what social norms ("tastes") prevail in society. A wide-spread taste for discrimination of women reduces the welfare of women. In this sense it is not a private affair. It may be objected that a preference for coffee will hurt the tea merchants. This is true, but they can change their trade more easily than women can change their sex. The "taste"-parlance tends to fade out these important problems.

The statistical theory of discrimination may explain why some indicators (like sex) convey probabilistic information about productivities and induce wage differentials (PHELPS, 1972). If social roles or stereotypes exist that actually trigger different behaviors of the groups, the observation that an applicant is female may signal a higher probability of unfavorable events in the prospective employment relation, perhaps a higher probability of terminating the employment relationship prematurely for family reasons. If the firm plans to invest in the worker, such a prospect will make the firm reluctant to hire a woman unless a lower wage or 
better productivity features compensate the drawback (LAZEAR and Rosen, 1990). As social roles are internalized by both males and females, corresponding behavioral differences are to be expected. In this way, such a theory ties social stereotypes to economic outcomes. Such discrimination is perfectly efficient, as the labels "male" or "female" signal that the workers differ in productivity, even if only probabilistically. From an efficiency point of view this warrants different treatment. Yet if the term "discrimination" is construed as referring to differential treatment of workers of equal productivity, the statistical theory of discrimination does not provide a theory of discrimination. It treats wage differentials between men and women just as other wage differentials. Further, it faces difficulties in accounting for group discrimination (CAIN, 1986, 724-9).

The monopsonistic theory of discrimination relates wage differentials not to productivity but to supply behavior (RoBINson 1969, 302-4). If supply behavior is shaped by social roles and stereotypes, the theory may account for forms of discrimination that do not relate to productivity but rather to social roles. In this spirit it has been suggested and empirically supported that discrimination may be traced to differential supply behavior of males and females (Schlicht 1982, Manning 2005, Ch. 7, Sulis 2007, Hirsch et al. 2008, Hirsch et al. 2009, Hirsch forthcoming). Women place more emphasis on non-pecuniary attributes of the workplace than men do. They value proximity to home and agreeable working hours while males are more responsive to monetary incentives. ${ }^{1}$ Hence labor supply of women, as seen from the point of view of the firm, will be less elastic than that of males, and this gives rise to discrimination, including group discrimination. ${ }^{2}$

The theory proposed here builds on the same behavioral assumption regarding supply behavior and develops a related idea in an efficiency-wage context. ${ }^{3}$ The outcome is again triggered by behavioral differences entailed by social roles and stereotypes and leads to group discrimination. In a sense, it provides a variant of the monopsonistic theory, yet arguably the selection wage mechanism seems more realistic than the monopsonistic one, as firms actually do engage in upgrading and downgrading of jobs (DEVEREUx, 2002, BütTNER et al., 2009).

\footnotetext{
${ }^{1}$ It may be conjectured that firms may use such non-monetary job features to attract women, giving rise to another mechanism. This idea is not pursued here in order to establish the argument that differential pay of equally productive workers is a possibility, if not a necessity, in an unregulated labor market. ${ }^{2}$ The assumption that female labor supply, as seen from the point of view of the firm, is less elastic than that of males does not rule out that market supply for women may be more elastic than that of males. Hirsch et al. (2008) discuss the issue and provide empirical evidence. 3 The fundamental idea of drawing on efficiency wages in order to explain discrimination goes back at least to Stiglitz (1973). Schlicht (2001, Section 5) provides a variant in the turnover context that generates job discrimination.
} 


\section{Conclusion}

The selection wage theory of discrimination ties discrimination to different supply behavior of the groups involved. Firms set wages in order to attract more qualified applicants. As women respond less to wage differentials than men, firms can use the wage mechanism more effectively for men than for women and this brings about a higher market wage level for men than for women.

An empirical support for the view emerges from combining empirical studies of monopsonistic discrimination with studies that emphasize the variability of hiring standards.

The welfare implications of the view have to be addressed in future research.

\section{References}

Becker, G. S. 1971, The Economics of Discrimination (Economic Research Studies), second ed., University Of Chicago Press, online at http://amazon.com/o/ASIN/0226041166/.

Büttner, T., P. Jacobebbinghaus, and J. Ludsteck 2009, "Occupational Upgrading and the Business Cycle in West Germany," Economics: The Open-Access, Open-Assessment E-Journal, 3, online at http://www.economics-ejournal.org/economics/discussionpapers/ 2009-34.

CaIn, G. G. 1986, "The Economic Analysis of Labor Market Discrimination: A Survey," in: O. Ashenfelter and R. Layard (eds.), Handbook of Labor Economics, chap. 13, pp. 693-785, Elsevier.

Devereux, P. J. 2002, “Occupational Upgrading and the Business Cycle," Labour, 16, 423-52, online at http://ideas.repec.org/a/bla/labour/v16y2002i3p423-452.html.

Glaeser, E. L., B. I. Sacerdote, and J. A. Scheinkman 2003, "The Social Multiplier," Journal of the European Economic Association, 1, 345-353, online at http://ideas.repec.org/ a/tpr/jeurec/v1y2003i2-3p345-353.html.

Hirsch, B. forthcoming, "The Gender Pay Gap Under Duopsony: Joan Robinson Meets Harold Hotelling," Scottish Journal of Political Economy.

Hirsch, B., M. KöNig, and J. Möller 2009, "Is There a Gap in the Gap? Regional Differences in the Gender Pay Gap," IZA Discussion Papers 4231, Institute for the Study of

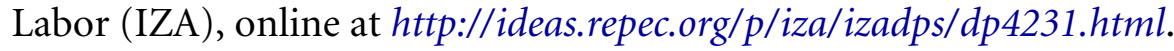


Hirsch, B., T. Schank, and C. Schnabel 2008, "Differences in Labor Supply to Monopsonistic Firms and the Gender Pay Gap: An Empirical Analysis Using Linked EmployerEmployee Data from Germany," Working Papers 1111, Princeton University, Department of Economics, Industrial Relations Section., online at http://ideas.repec.org/p/pri/indrel/ 1111.html.

Kahneman, D., J. L. Knetsch, and R. Thaler 1986, "Fairness as a Constraint on Profit Seeking: Entitlements in the Market," American Economic Review, 76, 728-41, online at http://ideas.repec.org/a/aea/aecrev/v76y1986i4p728-41.html.

Lazear, E. P. and S. Rosen 1990, "Male-Female Wage Differentials in Job Ladders," Journal of Labor Economics, 8, S106-23, online at http://ideas.repec.org/a/ucp/jlabec/ v8y1990i1ps106-23.html.

Manning, A. 2005, Monopsony in Motion: Imperfect Competition in Labor Markets, Princeton University Press, online at http://amazon.com/o/ASIN/0691123284/.

Marshall, A. 1920, Principles of Economics, 8th ed., London: Macmillan, online at http: //www.econlib.org/library/Marshall/marPtoc.html, reprint 1949, first edition 1890.

Phelps, E. S. 1972, “The Statistical Theory of Racism and Sexism," American Economic Review, 62, 659-61, online at http://ideas.repec.org/a/aea/aecrev/v62y1972i4p659-61.html.

Robinson, J. 1969, The Economics of Imperfect Competition, second ed., McMillan, London, first edition 1933.

Schlicht, E. 1978, "Labour Turnover, Wage Structure, and Natural Unemployment," Journal of Institutional and Theoretical Economics, 134, 337-46, online at http://econpapers. repec.org/paper/lmumuenec/1255.htm.

- 1981, "Reference Group Behaviour and Economic Incentives," Journal of Institutional

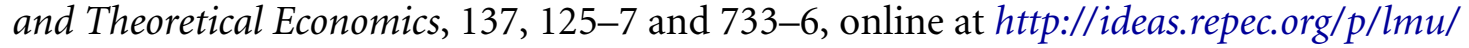
muenec/10623.html.

- 1982, "A Robinsonian Approach to Discrimination," Journal of Institutional and Theoretical Economics, 138, 64-83, online at http://www.semverteilung.vwl.uni-muenchen.de/ mitarbeiter/es/paper/schlicht_discrimination.pdf.

- 2001, "Job Rents in a Stylized Labor Market," in: S. K. Berninghaus and M. Braulke (eds.), Beiträge zur Mikro- und Makroökonomik, Festschrift für Hans-Jürgen Ramser, pp. 409-23, Springer-Verlag, online at http://econpapers.repec.org/paper/lmumuenec/1254. htm. 
— 2005, "Hiring Standards And Labour Market Clearing," Metroeconomica, 56, 263-279, online at $h t t p: / /$ ideas.repec.org/a/bla/metroe/v56y2005i2p263-279.html.

- 2007, "Wage Dispersion, Over-Qualification, and Reder Competition," Economics: The Open-Access, Open-Assessment E-Journal, 1, online at http://www.economics-ejournal.org/ economics/journalarticles/2007-13.

Solow, R. 1979, "Another Possible Cause of Wage Stickiness," Journal of Macroeconomics, 1, 79-82.

Stiglitz, J. E. 1973, "Approaches to the Economics of Discrimination," American Economic Review, 3, 287-95.

Sulis, G. 2007, "What Can Monopsony Explain of the Gender Wage Differential in Italy?" Working Paper CRENoS 200713, Centre for North South Economic Research, University of Cagliari and Sassari, Sardinia, online at $h t t p: / / i d e a s . r e p e c . o r g / p / c n s / c n s c w p / 200713$. html.

\section{Parameters Used For The Illustrations}

All graphs use the function

$$
f(\theta, w, W)=\left(1+\log \left(\frac{w}{W}\right)\right) \beta(\theta-0.5)
$$

over the range $\theta \in[0.5,1.5]$, where $\beta()$ denotes the probability density function of the Beta distribution with parameters $(3,5)$.

Figure 1 (a) uses $\frac{w}{W}=1$, Figure 1 (b) uses $\frac{w}{W}=1.2$.

Figure 2 (a) uses $\frac{w}{W}=1$ and $s=0.7$. This implies $n=0.85$ and $a=0.92$. Figure 2 (b) uses in addition $\frac{w}{W}=1.4$ which implies and $s=0.8$ and $a=0.97$.

Figure 3 (a) gives the productivity curve around $W=1$. The competitive wage is $w_{0}=0.86$. Figure $3(\mathrm{~b})$ adds the case $W^{\prime}=1.2$ with $w_{0}^{\prime}=0.91$. Figure $3(\mathrm{c})$ gives the wage $w^{*}=1.1$ forthcoming at $p=6.2$. 